\title{
LOS PROCEDIMIENTOS DE ATENUACIÓN EN LAS SERIES TELEVISIVAS ESPAÑOLAS ENTRE HUMORISMO Y CONSTRUCCIÓN DEL ETHOS
}

\author{
MITIGATION STRATEGIES IN SPANISH TV SERIES, BETWEEN HUMOUR AND ETHOS \\ CONSTRUCTION
}

\author{
Giovanna MAPELLI \\ Università degli Studi di Milano
}

Resumen:

Los diálogos de las series televisivas son un ejemplo de "oralidad recitada" (Nencioni, 1976), no espontánea, ya que proceden de un texto escrito, el guion. Sin embargo, para que los intercambios resulten más verosímiles y dinámicos, se intentan reproducir muchos de los elementos típicos de la conversación coloquial, entre ellos, los procedimientos atenuadores (Briz, 1998; Albelda, 2010).

Si se considera que la atenuación es una estrategia dentro de la actividad argumentativa y conversacional que busca la aceptación del oyente, y que consiste en suavizar, restar fuerza ilocutiva, reparar, no expresar todo lo que se quiere dar a entender (Briz, 2003; Briz y Albelda, 2013), puede ser un recurso que respalda la ironía y la comicidad de estos formatos (Ruiz Gurillo, 2012, 2013). Por otro lado, el recurso de la atenuación concurre en la construcción del ethos (Charaudeau y Maingueneau, 2002; Amossy, 2010), en la imagen discursiva de sí que sitúa al personaje en un imaginario discursivo que corresponde a un estereotipo. Dentro del marco teórico pragmalingüístico y mediante un análisis cualitativo, vamos a identificar qué estrategias atenuadoras se emplean y con qué funciones en doce guiones de la serie española Aída, emitida por Telecinco.

Palabras Clave: serie televisiva, oralidad recitada, atenuación, humor, ethos
Abstract:

TV series dialogues are an example of nonspontaneous, "fictional orality" (Nencioni, 1976) since they are based on a written text, the script. However, in order for dialogues to be more plausible and dynamic, they reproduce some of the mechanisms typical of colloquial conversation, including mitigation (Briz, 1998; Albelda, 2010).

If we assume that mitigation is an argumentative and conversational strategy that aims at obtaining the hearer's acceptance and consists of playing down the illocutionary force, providing communicative repairs and conveying unspoken messages (Briz, 2003; Briz y Albelda, 2013), it can be seen as a resource that enhances irony and comedy in these formats (Ruiz Gurillo, 2012, 2013). On the other hand, mitigation helps build ethos (Charaudeau y Maingueneau, 2002; Amossy, 2010) in the discursive self-image that identifies the character as a stereotype. Mitigation strategies and their functions will be identified in twelve scripts of Aida, a Spanish TV series broadcast by Telecinco, adopting a pragmatic approach and a qualitative analysis.

KEYWORDS: TV series, fictional orality, mitigation, humor, ethos 


\section{normas}

Los procedimientos de atenuación en las series televisivas españolas| Giovanna Mapelli

\section{LA COMEDIA DE SITUACIÓN}

En los últimos años, la serie televisiva se ha impuesto como género por excelencia de la programación de todas las cadenas, ocupa un lugar privilegiado en la parrilla y es de muy fácil acceso para el espectador. Esa programación afortunada, por una parte, contribuye a que los índices de audiencia sean muy altos y, por otra, se asegura la fidelización del público. Además, Carrión (2015) sostiene que las series se han vuelto paradigmáticas de nuestro momento histórico por la relativa brevedad de sus capítulos, por su capacidad de dar respuesta ficcional casi inmediata a la agenda sociopolítica, por la alta calidad técnica de muchas de ellas y por haberse adaptado a todos los canales de distribución (incluso Internet). Es más, Grasso (2006) afirma que buena parte del mejor cine actual está asociado a las series televisivas que, en algunos casos, se han convertido en verdaderos fenómenos sociales. De hecho, como afirma Bednarek (2015), las series construyen y reflejan realidades sociales, favorecen la implicación del público y crean otros discursos, como por ejemplo las reacciones de los fans, los comentarios críticos o los cotilleos acerca de la misma y de sus protagonistas.

Dentro de las series, destaca, sin lugar a dudas, el subgénero de la comedia de situación o sitcom que, por su brillantez, alcanza cada vez más éxito entre los telespectadores y es una de sus opciones favoritas de consumo.

Su característica principal es la repetición de la estructura narrativa y de los personajes. El modelo tradicional prevé tres momentos: a. ruptura del equilibrio inicial por la presencia de un problema; b. reacción de los protagonistas e intentos de resolverlo a través de situaciones cómicas; c. resolución y restablecimiento del orden inicial. Si bien existen elementos de continuidad que atan un capítulo con otro, por ejemplo, las relaciones sentimentales que van surgiendo entre los personajes, en general, podemos decir que cada entrega es autónoma, es decir, surge el conflicto y se resuelve, por lo que no queda nada pendiente para el episodio siguiente; esto convierte a los personajes, marcados psicológicamente como antihéroes, en inmutables y predecibles (Menduni, 2002: 145). Sabemos cómo se van a comportar ante las distintas situaciones, ya que las relaciones entre ellos no varían en términos de poder/estatus, contacto/solidaridad y tipo de interacción. En este entramado más o menos monótono, en el que los caracteres tienden a mantener cierta estabilidad para favorecer la identificación del público con los personajes (Bednarek, 2011: 193), el lenguaje desempeña un papel fundamental en el éxito del programa (Grignaffini, 2004; Grasso, 2006); es más, los mismos personajes adquieren su propia identidad a través de la práctica discursiva (Yus, 2015) y gestionan sus relaciones interpersonales (Bubel, 2011: 226), para que el público se sienta identificado.

Mapelli (2016) observó que para favorecer esta identificación por parte del telespectador, en las comedias se halla la mayoría de los rasgos de la lengua hablada como, por ejemplo, léxico reducido, palabras malsonantes, jergas marginales, vocativos, marcadores conversacionales, modismos, etc. e, incluso, aquellos mecanismos que otorgan discontinuidad al discurso (vacilaciones, titubeos, reformulaciones, enunciados suspendidos, etc.) propios de la improvisación del habla espontánea y que suelen omitirse en otros géneros de ficción, como las películas. Además, la finalidad interpersonal de los diálogos y de la relación con el público, cuyo objetivo es provocar la risa, favorecen la aparición de una serie de recursos expresivos y elativos. De hecho, se rastrearon 


\section{normas}

Los procedimientos de atenuación en las series televisivas españolas| Giovanna Mapelli

numerosos procedimientos de intensificación (afijos, metáforas, símiles, hipérboles, etc.) utilizados, por un lado, para jugar con la musicalidad y otorgar ritmo al capítulo y, por otro lado, para aumentar más sorpresa a lo que decía a continuación el personaje y, de esta forma, que funcionara mejor el gag (Mapelli 2016).

Por lo tanto, la variedad de lengua de las series que entra dentro lo que se ha descrito como "parlato simulato" (Alfieri, 2008: 178-180), "oralidad prefabricada" (Chaume, 2001: 80), o "parlato-recitato" (Nencioni, 1976: 186) se acerca, en realidad, al registro coloquial espontáneo, es decir, en estos formatos se intenta reproducir la espontaneidad de la conversación coloquial a pesar de que sea un intercambio construido y programado en un guion escrito. Esta simulación del habla cotidiana, recalcada por la destreza del actor, quien actúa en directo y con público ${ }^{1}$, junto con los temas tratados, que son el retrato irónico de los conflictos sociales que más sufre la población española (como la prostitución, la homosexualidad, el alcoholismo, la inmigración, la carga que supone para una madre criar en solitario a sus hijos, etc.), sirve para que el público tenga la ilusión de asistir a una escena de la vida real: los diálogos resultan verosímiles, creíbles y eficaces y consiguen así activar mecanismos de identificación por parte de los espectadores y disminuir la distancia entre público y personaje. Los diálogos son un reflejo de lo que los guionistas escuchan en la calle a personas reales (entrevista personal al guionista Raúl Díaz) conforme con su clase y educación, y están construidos sobre la base de su conocimiento y de su experiencia del mundo y del conocimiento del mundo que prevén tenga su público (Bubel, 2011: 229).

Además, el lenguaje de las series es tan importante que deja un legado: muchas expresiones de los personajes se trasforman en clichés que caracterizan al habla de los mismos y pasan a la lengua común, creando un continuo transvase de la lengua espontánea a las series y de las series al habla cotidiana (pensemos en el famoso "un poquito de por favor" de Emilio en Aquí no hay quien viva o "No tengo el chichi para farolillos", o "Pero esto qué eeeeeees" o "Tiritiritiriri" de Mauricio en Aída)².

\section{OBJETIVOS Y MARCO TEÓRICO}

Las series televisivas han sido analizadas en diferentes ámbitos, como el audivisual, el cultural y el sociológico. Sin embargo, en las últimas décadas, han ido aumentando los estudios en el campo lingüístico, en el que se han enfocado en particular las series norteamericanas, para reflexionar sobre el discurso y el registro (Quaglio, 2009; Ayliffe, 2011; Bednarek, 2010, 2011, 2012), y sobre la utilidad de este lenguaje para la enseñanza de las lenguas extranjeras (Webb, 2010), la traducción audiovisual o la subtitulación (Baños Piñero et alii, 2013; Bonsignori y Brutti, 2014)3. En cuanto a las series españolas, se enumeran los estudios de Baños Piñero (2009, 2012, 2013), de Tonin (2014) y La Forgia y Tonin (2016) o de Gómez Capuz (2001) sobre los problemas de traducción audiovisual, de Mapelli (2016) sobre los aspectos de la coloquialidad y la intensificación y Chierichetti (en

\footnotetext{
${ }^{1}$ Con este peculiar sistema de grabación, derivado de los hábitos americanos, la puesta en escena gana en espontaneidad y naturalidad.

${ }^{2}$ En general, estas expresiones suelen ser aportaciones del actor al texto que hacen tanta gracia a los guionistas que las vuelven a utilizar en capítulos posteriores (Raúl Díaz, entrevista personal).

${ }^{3}$ Para una mayor profundización de los estudios sobre las series norteamericanas cfr. Bednarek (2015).
} 


\section{normas}

Los procedimientos de atenuación en las series televisivas españolas| Giovanna Mapelli

prensa) acerca del discurso amoroso y la construcción discursiva de la identidad de los personajes.

A diferencia de estos estudios, que se basaban en las transcripciones ${ }^{4}$, nos centramos aquí en una cala de doce guiones ${ }^{5}$, de la serie televisiva Aída, el primer spin-off español de otra serie muy consolidada y de éxito, 7 vidas, producida por Globomedia para la cadena

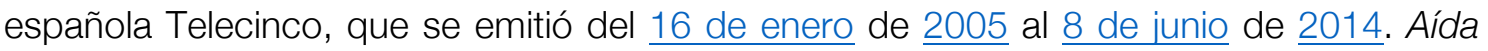
narra la vida de una familia de clase humilde que reside en el ficticio barrio madrileño de "Esperanza Sur". Su protagonista, Aída, que proviene de 7 vidas, incorpora con ironía y sentido del humor sus dificultades para hacer frente a la vida como mujer separada, madre de dos hijos muy peculiares y trabajadora con un bajo nivel de cualificación. Como destaca su director y productor ejecutivo, Nacho G. Velilla, "en la ficción televisiva, donde reina el éxito tanto profesional como sentimental, no se había reflejado todavía el grupo de gente que lo pasa mal para llegar a fin de mes y cuyo fin no es el éxito, sino la supervivencia. No veremos una familia feliz, sino que aspira a serlo; no veremos una persona establecida en un trabajo, sino personas que aspiran a buscar trabajo"6. La serie contó con gran número de espectadores en sus diez temporadas emitidas y fue líder de audiencia en su primera emisión ${ }^{7}$. Somos conscientes de que el guion no es apropiado para las investigaciones sobre conversaciones reales (Forchini, 2012 en Bednarek, 2015), al ser un texto escrito que aún no ha sido reinterpretado oralmente por el actor (Gregory y Carroll, 1978). Sabemos, además, que los actores cuando actúan tienen la habilidad de cambiar el diálogo original y de poner en escena un intercambio más espontáneo y natural ${ }^{8}$. Sin embargo, creemos que el guion es un excelente punto de partida para observar qué estrategias discursivas utilizan los guionistas mismos para alcanzar los objetivos de la serie, en nuestro caso, un fin cómico. No olvidemos que los diálogos de las comedias tienen unas reglas propias para resultar chistosos y cada palabra está sopesada por los autores, como afirma Rául Díaz en una entrevista personal9.

Dentro del marco teórico pragmalingüístico y mediante un análisis cualitativo, vamos a describir, en particular, qué estrategias lingüísticas atenuadoras se emplean, a identificar las funciones que desempeñan, y a observar si pueden ser un recurso que respalde la ironía y la comicidad de este género televisivo (Melloni, 2004; Ruiz Gurillo, 2012, 2013).

La atenuación es una categoría pragmática al servicio de la comunicación (Fraser, 1980, Briz, 1998, 2003, entre otros), y es una estrategia dentro de la actividad argumentativa y

\footnotetext{
${ }^{4}$ Excepto Chierichetti (en prensa) que utiliza guiones originales de la serie LEX.

${ }^{5}$ Agradezco a Andrés Cuenca Lillo, director de casting de la productora Globomedia, y a Raúl Díaz Rivas, guionista de la serie, el haberme proporcionado los guiones originales. De la temporada 4, hemos estudiado los siguientes capítulos: 43. El ostión; 44. El enano oscuro; 51. El retorno del gay; 53. Charly y las fábricas de prostitutas; 54. Entre pillas anda el juego; 55. Hasta que llegó la O.R.A.; 56. Así en el cielo como en la tienda; 57. El atraco a las 10; 58. Leaving Esperanza Sur. De la temporada 5: capítulo 68. Oro salvaje. De la temporada 6, los siguientes capítulos: 89. Hasta que llegó Soraya; 90. "La familia mata".

${ }^{6}$ http://www.formulatv.com/noticias/756/el-primer-spin-off-de-una-serie-espanola-llega-de-la-mano-de-aida/ (10/10/2016) ${ }^{7} \mathrm{http}: / /$ www.formulatv.com/noticias/758/audiencias-aida-arrasa-a-la-competencia-con-casi-7-millones-de-espectadores/

${ }^{8}$ De hecho, si los guiones imitan la lengua hablada, eliminando las redundancias (Alfieri, 1997 en Alfieri y Bonomi, 2012), en las transcripciones, se han observado todos los elementos que quitan la linealidad del texto escrito (Mapelli 2016). Dejamos para investigaciones futuras el cotejo de los guiones con las trascripciones de los mismos capítulos de la serie y la investigación de lo que aportan los actores al texto durante la actuación.

${ }^{9}$ Es importante subrayar que para crear el guion de un capítulo se tarda aproximadamente un mes, lo cual indica que nada está improvisado.
} 


\section{normas}

Los procedimientos de atenuación en las series televisivas españolas| Giovanna Mapelli

conversacional que busca la aceptación del oyente, que consiste en reducir el valor significativo de un enunciado (Lakoff, 1972) y en suavizar, restar fuerza ilocutiva, reparar, no expresar todo lo que se quiere dar a entender (Briz, 2003; Briz y Albelda, 2013; Caffi, 1999). De acuerdo con Briz (2003), destacamos que solo en ocasiones puede ser instrumento o manifestación de una función social, la de la imagen cortés. Es decir, la atenuación no necesariamente cumple una función de cortesía o manejo de la imagen de los hablantes.

Cabe subrayar que la atenuación afecta a dos ámbitos: el dictum (atenuación semánticopragmática, Briz, 1998) y el modus (atenuación pragmática, Briz, 1998).

Asimismo, vamos a indagar si la atenuación concurre a la construcción del ethos, es decir, de la imagen de sí creíble y eficaz, que sitúa al personaje en un imaginario discursivo compartido por el grupo social de referencia y que corresponde a un determinado estereotipo (Charaudeau y Maingueneau, 2002; Amossy, 2010) ${ }^{10}$. De hecho, el enunciador pone en escena a su persona de una forma programada y utiliza el lenguaje como recurso para construir su identidad de acuerdo con el propósito comunicativo y con las expectativas del público en un proceso dinámico que nace de la interacción (Charaudeau y Maingueneau, 2002; Amossy, 2010). El enunciador, por lo tanto, consigue dar una impresión positiva o negativa al interlocutor a través de su discurso y de su manera de expresarse (Maingueneau en línea).

\section{ANÁLISIS DE LOS GUIONES}

Es cierto que en nuestro corpus la atenuación no es un recurso muy frecuente (respecto, por ejemplo, a la intensificación), puesto que se trata de conversaciones prototípicas en las que hay una relación vivencial de proximidad entre los protagonistas (son amigos, vecinos con experiencias comunes y compartidas), el contenido enunciativo es cotidiano (de hecho, las temáticas tratadas, como hemos dicho, están al alcance de todos), y la relación es de igualdad (no hay jerarquía, sino que existe solidaridad entre los personajes), el tono informal y el fin interpersonal (Briz, 1998; Briz y Albelda, 2013). Sin embargo, hemos encontrado una buena muestra de ella, con diferentes objetivos comunicativos.

Para la identificación de las tácticas de atenuación, partimos del esquema propuesto por Albelda y Cestero (2011) que reconoce los siguientes tipos:
a) minimizar o difuminar la cantidad o cualidad de lo dicho;
b) rebajar la aserción expresándola en forma de duda o de incertidumbre;
c) desfocalizar los elementos de la enunciación personal o temporal;
d) acotar o restringir lo dicho;
e) justificar;
f) corregir o reparar;

\footnotetext{
${ }^{10}$ El concepto de ethos, junto con el logos y el pathos, deriva de la retórica clásica y sirve dentro del discurso público para persuadir a la audiencia. Se trata de la imagen que el orador construye a través de su manera de decir (gestos, entonación, postura, etc.). Es, por lo tanto, la cualidad moral del orador la que lo hace digno de confianza. Goffman (1973) llama présentation de soi a esta imagen de nuestra persona que proyectamos en las interacciones cotidianas. Aquí, en cambio, aplicamos la noción de ethos al análisis del discurso, de acuerdo con Maingueneau (en línea), que introduce el concepto de ethos discursivo para referirse a nuestra presentación verbal ante los demás.
} 


\section{normas}

Los procedimientos de atenuación en las series televisivas españolas| Giovanna Mapelli

g) realizar concesiones;

h) implicar al tú en lo dicho por el hablante;

i) formular actos directivos de forma indirecta.

La primera táctica corresponde a la atenuación de lo dicho (Briz, 1998, 2003) y a los bushes de Caffi (1999), que minimizan la cantidad o cualidad de lo dicho. Las demás se consideran atenuación del modo, puesto que inciden en el acto de habla y sobre los papeles de los interlocutores en la enunciación (Albelda y Cestero, 2011).

En los apartados siguientes, observaremos cuáles de estos movimientos se emplean y con qué funciones.

\subsection{Minimizar o difuminar la cantidad o cualidad de lo dicho}

La lengua dispone di unos mecanismos que sirven para minimizar la cantidad y la calidad de lo dicho. En nuestro corpus, se han encontrado, por ejemplo, los sufijos diminutivos. En (1), Soraya, la hija mayor de Aída, vuelve a casa después de mucho tiempo y al hablar con Lorena utiliza el diminutivo cariñoso "hermanita" y para no dañar la imagen de la hermana afirma que antes era "regordita":

(1) SORAYA: ¡Yo también te he echado de menos, hermanita! Joer, la última vez que te vi eras así, regordita y llena de pecas (cap. 89).

Asimismo en (2), Luisma está hablando con Jonathan y le confía que Esther no significó nada para él; en ese momento, la chica sale del baño enfadada porque ha escuchado estas palabras: Luisma intenta excusarse, pero las disculpas no funcionan y Esther le pega una bofetada. Aquí se utiliza, además de los desarmadores y de las preguntas con función fática, el diminutivo "pistita" junto con la unidad fraseológica "lo tengo en la punta de la lengua", que aumentan la evidencia de que se está diciendo lo contrario. Es más, el uso reiterado de "cari" provoca la risa, porque Luisma hace exactamente lo contrario de lo que está diciendo: con la repetición de vocativo afectivo demuestra que no recuerda efectivamente el nombre de la chica. Se trata, por lo tanto, de un recurso lingüístico basado en el contraste (Ruiz Gurillo, 2012) que crea un enunciado con una clara intención irónica (Provencio Garrigós, 2009; Timofeeva, 2009):

(2) LUISMA: Pues claro que no, si tu profesora es la típica mujer pomada: [...] Joer, pero si no me acuerdo de su nombre. Que cuando estoy con ella la llamo cari para no equivocarme.

LUISMA: eh.. eh.. ¡Hola cari! No habrás creído que no me acuerdo de tu nombre, ¿verdad cari? Eh... joder, si lo tengo en la punta de la lengua, ¿Me das una pistita, cari? (cap. 48).

Asimismo, para minimizar la cantidad se pueden utilizar cuantificadores y modificadores. En (3), Aída está ayudando a Paz a librarse del cadáver que han metido en una furgoneta. Todos suben al coche y Aída se pone al volante, intenta meter las llaves en el contacto, pero no lo consigue y procura justificar el vocativo 


\section{normas}

Los procedimientos de atenuación en las series televisivas españolas| Giovanna Mapelli

ofensivo "idiota", que es el elemento desencadenante, recurriendo a la fórmula esterotipada "Perdona" y a un cuantificador "un poco", que viola la máxima de cantidad (es decir, el interlocutor debe inferir lo contrario, 'Aída está muy nerviosa') y a esto se suma un largo rodeo justificativo introducido por "pero" y el nexo "es que". En este caso la atenuación dialógica tiene una función de autoprotección de la imagen del yo:

(3) AIDA: ¡Lo intento pero la llave no entra!

PAZ: Porque estás metiendo las de la casa, idiota.

AIDA: Perdona si estoy un poco nerviosa, iPero es que hace mucho que no conduzco una furgoneta robada con un cadáver que busca la policía! Además que no es culpa mía, que esto no arranca (cap. 43).

En (4), Aída está acusando a Chema de decir tonterías, el vecino se defiende con una justificación introducida por el "si" replicativo-reactivo (Calvi, 2007) y el minimizador "solo":

(4) AIDA. ¡Un tonto a las tres es lo que eres! ¡Que te calles, Martínez! Que no paras de decir chorradas.

CHEMA: Pero si yo solo he dicho que voy a hacer unas gestiones, a ver si nos dan alguna subvención y... (cap. 51).

\subsection{Rebajar la aserción expresándola en forma de duda o incertidumbre}

Esta estrategia permite reducir nuestro grado de seguridad con respecto a lo que decimos, a través de verbos y adverbios modales de pensamiento, probabilidad, duda, como creer, pensar, ser posible, quizás, o a lo mejor.

En (5), Soraya está hablando de su marido Ángel, que la pegaba, y sobre la posibilidad de denunciarlo:

(5) LORENA: ¿Que todavía no le has denunciado? ¡Pues tienes que hacerlo ya! Que se pudra en la cárcel ese cabrón.

SORAYA: Pues es que no es tan fácil, es el padre de mi hija, y... y... él antes no era así. A ver, yo sé que le tengo que denunciar y lo voy a hacer, pero... creo que voy a esperar un poco (cap. 89).

En (6), Luisma se dirige a Chema y emplea no solo el minimizador con diminutivo ("un poquito", "un pelín"), sino también un adverbio de duda para rebajar la fuerza de los primeros dos insultos a su amigo, ya que la última afirmación tiene una carga intensificadora ("feo de cojones"). Aquí el efecto cómico nace precisamente de la contraposición entre atenuación e intensificación:

(6) LUISMA: No. Te estoy diciendo que te cases con Macu. Aunque claro, tú lo tienes peor. Entre que tienes un poquito de mala suerte, quizás un pelín torpe y eres feo de cojones (cap. 89). 


\section{normas}

Los procedimientos de atenuación en las series televisivas españolas| Giovanna Mapelli

En (7), se emplea "a lo mejor", que aminora la fuerza de lo expresado (Briz 2003) y protege la imagen de ambos interlocutores, para acompañar tanto la intervención intensificadora de Aída como la atenuación de Chema. También en este caso el efecto cómico nace de la contraposición entre atenuación e intensificación ("tan pesado"):

(7) AIDA: Pues a lo mejor no va nadie a las reuniones porque eres un pesado.

CHEMA: Pues a lo mejor no soy tan pesado si me llevan eligiendo presidente 10 años (cap. 51).

Igualmente, se pueden utilizar verbos, adverbios o estructuras verbales que expresan incertidumbre, incompetencia o fingimiento de ignorancia, como no saber, no estar seguro, seguramente...

En (8), tras descubrir que su hija ha sido víctima de malos tratos por parte de su marido, Aída decide protegerla. Durante una pelea entre Soraya y su esposo, Aída interviene y la disputa tiene un trágico desenlace: Ángel se queda inerte en el suelo. En este ejemplo, las reformulaciones y los titubeos, rematados por "no sé", sirven para atenuar el estado de confusión de la chica que ha asistido al homicidio:

(8) AIDA: Ay, mierda, i¿qué he hecho?! ¡Que me he cargado a un hombre! ¿Soraya, tú estás bien?

SORAYA: Sí, sí... bueno no. ¡No sé! Ay, Dios, no tenía que haber venido aquí. En menudo lío te he metido (cap. 90).

\subsection{Desfocalizar los elementos de la enunciación}

A diferencia de géneros más estructurados como las entrevistas semidirigidas (Albelda y Cestero, 2011), la desfocalización de elementos no es una táctica muy empleada. De hecho, la impersonalización se utiliza sobre todo en los géneros más estructurados; en cambio, en la conversación coloquial no es un procedimiento muy frecuente.

En (9), con función de autoprotección, se recurre a movimientos de reformulación argumentativa ("según dicen mis fuentes"), que impersonaliza y evita el compromiso del hablante en relación con la verdad de lo dicho. Aída está discutiendo con Chema, con el que está compitiendo en las elecciones como presidente de la Asociación de Padres de Alumnos del colegio y encubre su opinión con la de otros ("lo que dicen mis fuentes"). En este caso se usa una pregunta retórica y el adverbio "presuntamente", que tiene un uso restrictivo del valor de verdad de la aserción (Kovacci, 1999: 758), y relativiza la verdad del enunciado; además, el nombre solo está señalado con las iniciales para resaltar el anonimato:

(9) AIDA: $Y$ no quiero acusar a nadie, pero el señor " $C$ punto, $M$ punto" contrató presuntamente para arreglar el patio a un señor apellidado Martínez. ¿Será familia suya? No lo sé. Yo solo repito lo que dicen mis fuentes.

CHEMA: [...] ¡No te consiento que me llames ladrón!

AIDA: ¡Presuntamente, he dicho presuntamente! (cap. 51). 


\section{normas}

Los procedimientos de atenuación en las series televisivas españolas| Giovanna Mapelli

Es poco frecuente también la modificación temporal del verbo, es decir, el empleo del condicional en lugar del presente.

En (10), después de la muerte de su tío, Mauricio piensa que va a heredar toda su riqueza, pero luego ante el notario descubre que no es así, porque se ha casado con un hombre y, por lo tanto, no podrá ser padre:

(10) NOTARIO: Lo que intentaba decirle es que su tío dejó muy claro que la herencia sería para el primero que se casara... perpetuando su apellido con un hijo legítimo. Vamos, que no hereda (cap. 90).

\subsection{Acotar o restringir lo dicho}

En nuestro corpus, no se han encontrado muchos mecanismos que acoten cautelosamente el ámbito de lo dicho. En (11), se limita la opinión expresada a un determinado ámbito ("al menos"):

(11) LORENA: Joer, es que hemos buscado por todos lados. Si al menos volviera a delirar y nos diese otra pista. (Cae) Claro, eso es lo que hay que hacer (cap. 68).

\subsection{Justificar}

La justificación, en cambio, es uno de los movimientos comunicativos más recurrentes en esta serie, por la relajación pragmática de los encuentros interactivos y por el hecho de que muchas situaciones cómicas resultan precisamente del choque entre los personajes.

Se rastrean justificaciones y excusas de lo dicho o del decir. En particular es productivo el empleo de estructuras y conectores lexicalizados (es que, lo que pasa es que, que), como en (12), en el que Luisma pide disculpas a Esther porque tuvo que encerrarla en una habitación cuando llegó Eugenia, su madre. Utiliza la fórmula estereotipada ("siento") y el conector prágmatico con valor justificativo ("es que"). También aquí el efecto cómico nace de la contraposición entre atenuación e intensificación ("eres una fiera"):

(12) LUISMA: Siento lo de antes, pero... es que era mi madre y... no me deja tener animales en casa. Y Claro, como tú eres una fiera... (cap. 56).

En (13), Mauricio quiere autoproteger su imagen, librándose de la acusación de que en su bar se había organizado una timba; el uso del marcador conversacional "si", en este caso, adquiere un valor justificativo-atenuador:

(13) MAURICIO: [...] una timba, dice. Si era una partida entre amigos que solo quieren divertirse (cap. 43).

\subsection{Corregir o reparar}

Cuando ya se ha producido un daño a la imagen o intencionadamente se va a realizarlo, el locutor intenta restaurar el orden para minimizar el desacuerdo. Esta estrategia está 


\section{normas}

Los procedimientos de atenuación en las series televisivas españolas| Giovanna Mapelli

vinculada, por lo tanto, al deseo de salvaguardar la imagen de los interlocutores (Brown y Levinson, 1987; Briz, 1998). Huelga decir que es uno de los mecanismos más explotados en nuestro corpus, puesto que la atenuación de la disconformidad dialógica y la protección monológica de la propia imagen (bueno, pues, hombre, etc.) producen el efecto cómico porque discrepan de lo que se pone en escena o porque otorgan un carácter espontáneo al enunciado.

En (14), el marcador "bueno" sirve para atenuar y rectificar una afirmación precedente del hablante (Martín Zorraquino y Portolés, 1999); en este intercambio con Aída, Paz intenta rebajar su "solo sé que he matado a un hombre con mis propias manos". Se trata de una atenuación que se apoya en la colaboración del público que sabe que ella no quería matar al diplómatico italiano, sino que este falleció durante el acto sexual con ella. Es una atenuación momentánea, ya que el uso del "pero" adversativo introduce la conclusión que se tiene que tener en cuenta en la prosecución del discurso ("pero es igual”). Además, la última afirmación tiene valor intensificador, puesto que está en una exclamación y tenemos una repetición ("lo he matado, lo he matado"):

(14) PAZ: ¡No lo sé! ¡No lo sé! ¡Solo sé que he matado a un hombre con mis propias manos! Bueno, con mis manos precisamente no, pero es igual ¡Lo he matado, Aída, lo he matado!

Por su parte, en (15), Aída procura aliviar la culpa de su amiga, reparando su imagen amenazada por la declaración "Lo he matado, lo he matado". Aída recurre a un "que" reactivo ("que no"), pero luego va a matizar que no lo ha matado, sino que solo ha hecho desaparecer el cadáver. Además, en este caso, se produce la risa, la misma Aída se ríe cuando pronuncia la frase:

(15) AIDA: Que no, que tú de lo único que tienes culpa es de que no vayan a poder cerrar la tapa del ataúd (cap. 43).

En (16), Aída intenta rebajar la fuerza del insulto de Luisma de que ella es una cebolleta, con el marcador "bueno":

(16) LUISMA: [....] él nunca se coscará de que sale con una cebolleta de metro cuarenta

AIDA: Bueno tampoco estoy tan mal. Vale, no llego al ocho como tú Paz, pero al siete con cinco (cap. 44).

En (17), en cambio, "bueno" actúa de minimizador de un piropo:

(17) PABLO: Para mí es importante estar rodeado de cosas bellas. Porque la belleza no solo se ve con los ojos también se siente. $Y$ ahora la estoy sintiendo. AIDA: Sí, es que el piso está decorado con mucho gusto.

PABLO: No tonta, es por ti. [...] Debes de ser preciosa ¿A que sí?

AIDA: Bueno, no soy yo quien lo tiene que decir (cap. 44). 


\section{normas}

Los procedimientos de atenuación en las series televisivas españolas| Giovanna Mapelli

El marcador conversacional "hombre" se emplea como atenuador de desacuerdo parcial para aminorar la disconformidad. En (18), Mauricio, que está recaudando fondos, tiene el bar lleno de gais. A una expresión intensificadora con matiz sexual ("si hay que poner el culo, lo pongo"), Tony responde mitigando la gravedad de la situación, empezando su intervención con "no, hombre":

(18) MAURICIO: ¿Y qué quieres que haga? Yo necesito apoyos y estos mueven a mucha gente [...] Además, que no tiene nada de malo defender sus banderas y sus colores con orgullo. Y si hay que poner el culo, lo pongo.

TONY: No, hombre, que tampoco te van a pedir tanto; que este colectivo es más tolerante de lo que parece (cap. 55).

También, encontramos la petición de disculpas con la misma función de reparar o corregir lo que se acaba de pronunciar. Se han encontrado muchas formas esterotipadas (perdón, perdona, por favor...) para subsanar la intromisión en el territorio del yo. En (19), Aída llega con una bandeja de hielo y golpea la cabeza de su hija, Lorena. Le pide perdón, añade una pregunta retórica y después propone una solución para quitarse aún más el peso de la culpa con el humor:

(19) AIDA: Uy, perdona, ¿te he hecho daño? Mira el lado bueno, ya tienes hielo para ponerte (cap. 59).

\subsection{Realizar concesiones}

Esta estrategia se suele encontrar en la toma de turno, cuando se acepta parcialmente lo afirmado por el interlocutor y después se discrepa, minimizando el desacuerdo. En (20), Mauricio reconoce la posibilidad de que pueda casarse, pero con el adversativo "pero", se aleja de lo dicho; es más, introduce un enunciado intensificado "estaré gastándome el dinero en la triple pe: putas, puros y más puros". La oposición atenuación e intensificación crea el gag:

(20) TONY: Oye maricón no te pongas flamenco, que yo también me puedo casar, ¿eh? Que muchos hombres me han ofrecido ya un anillo.

MAURICIO: Sí, pero cuando tú encuentres a alguien, yo estaré como todos los casados: gastándome el dinero en la triple pe: putas, puros y más puros (cap. 90).

\subsection{Implicar al tú-oyente en lo dicho}

Se emplean fórmulas fáticas (¿no?, ¿vale?, ¿Qué te parece?) de petición de consentimiento al tú para involucrarlo en la evaluación de lo dicho por el locutor. En (21), Jonathan, mirando al cielo para cerciorarse del tiempo, busca la cooperación del interlocutor, para recibir una respuesta afirmativa:

(21)JONATHAN: [...] Aunque parece que está abriendo ¿no? El día. Parece ¿no?

Asimismo, para resultar menos contundente en la decisión, y pedir la colaboración del interlocutor, se pueden emplear estructuras sintácticas inacabadas, dejando que este 


\section{normas}

Los procedimientos de atenuación en las series televisivas españolas| Giovanna Mapelli

llegue a la conclusión por su cuenta. En (22), Macu ha robado dinero del bar de Mauricio, y la chica intenta disculparse no solo con un cuantificador minimizador ("eran unos céntimos de nada"), que ya hemos comentado, sino también con la contraposición entre "el bote lleno" y "el bolsillo vacío" y la frase suspendida, para lograr el perdón de Mauricio:

(22) MAURICIO: ¡Inmaculada qué vergüenza! [...] ¡¿Cómo has podido hacer algo así?!

MACU: Eh...Vale, lo siento. Joer, es que el bote de las propinas estaba tan lleno, y mi bolsillo tan vacío... Pero eran unos céntimos de nada.... (cap. 57).

\subsection{Formular actos directivos de forma indirecta}

Existen actos de habla que transmiten una intención comunicativa concreta, aunque no está reflejada explícitamente en su codificación; por lo tanto, lo que se pide, solicita, sugiere, pregunta... está encubierto.

En las series, se prefiere ser directos y firmes; de todos modos, en algunas ocasiones tenemos ejemplos de actos directivos indirectos. En (23), Aída está ligando con Pablo, pero se da cuenta de que con sus preguntas está amenazando la imagen del chico. Se usan, por lo tanto, mecanismos de atenuación de cortesía negativa para reparar una intromisión en el territorio del otro, salvaguardando tanto el tú como el yo. De hecho, destacamos el movimiento concesivo ("No es que quiera saber") con el cual la mujer mitiga la invasión del terreno del tú y solicita de forma atenuada una información ("si tiene o no pareja"), la expresión desarmadora ("que seguro que la tendrá") con la que se atenúan las peticiones directas. Igualmente, el diferidor "a ver" que introduce la especificación "A ver, digo el banco, no usted", sirve para atenuar la pregunta "¿está libre?", que era una interrogación directa para saber si estaba casado o no. Además, el doble sentido de la palabra "libre", que puede referirse tanto al chico como al banco, permite que Aída disimule su pregunta:

(23) AIDA: Eeeh, hola ¿Está libre? A ver, digo el banco, no usted. Vamos que si está solo. Solo ahora, no es que quiera saber si tiene pareja o no. Que si no la tiene mejor para mí. Quiero decir que seguro que la tendrá porque es usted muy atractivo y elegante.

PABLO: ¿Me estás tirando los tejos?

AIDA: Huy, no perdón, perdón, lo siento mucho, esta boca, que me pierde. De hecho ya me iba (cap. 44).

En (24), Eugenia y Lorena están asustadísimas en el sofá viendo una película de terror. Al final, a pesar de todo, Lorena invita a la abuela a ver la segunda parte de la película, pero Eugenia recurre a una excusa. Los motivos evitan la conclusión directa ('No quiero'), y minimizan la respuesta negativa (Briz, 1998):

(24) LORENA: Pues... a mí me ha encantando. Sobre todo cuando ahorcan a la chica con sus intestinos. Y lo que ha tardado en morir, ¿eh, abuela? Mañana mismo alquilo la segunda parte. (cabronceta) ¿A qué hora te viene bien? EUGENIA (cagada) ehhh... uff mañana estoy muy liada. Ya si eso algún día me lo cuentas (cap. 44). 


\section{normas}

Los procedimientos de atenuación en las series televisivas españolas| Giovanna Mapelli

\section{CONCLUSIONES}

El éxito de las series televisivas se debe, por una parte, a las temáticas cotidianas tratadas y a los problemas a los que tenemos que enfrentarnos en la vida; por otra parte, a la comicidad y al humor e ironía con las que se perfilan los contenidos.

Del análisis se desprende que los procedimientos de atenuación no son un recurso muy explotado, puesto que se trata de conversaciones coloquiales prototípicas (Briz 1998) en las que se presenta cierta inmediatez comunicativa y, por lo tanto, una relajación lingüística, pragmática y social que conlleva un menor control de lo producido y una menor frecuencia de la actividad atenuadora (Briz y Albelda, 2013). Como ocurre en la conversación espontánea, en nuestro corpus la atenuación es una estrategia que se emplea sobre todo cuando el discurso es polémico o existe desacuerdo en los interlocutores o es necesario justificarse.

Sin embargo, en algunos casos, cabe interrogarse sobre el grado de 'sinceridad' de la atenuación, ya que creemos que en la comedia, esta se revela más bien como un microacto dentro del macroacto de la intensificación. Los guionistas, así como atestigua uno de ellos, fuerzan los diálogos con todos los recursos de la lengua para alcanzar sus fines. La atenuación es, por lo tanto, una estrategia que respalda la intensificación y amplifica el efecto cómico-humorístico, objetivo principal de las series, puesto que, en muchos casos, el enunciado atenuado choca con lo que está ocurriendo en la escena o con el enunciado sucesivo intensificado.

En conclusión, las estrategias rastreadas contribuyen a la construcción discursiva de la imagen, es decir, del ethos del actor; este las esgrime para incidir en la situación de enunciación y para ejercer influencia en el público. En cuanto al ethos del personaje, su componente discursivo interviene para consolidar una imagen cómica, incluso en situaciones de polémica o de contraste con otros personajes. Los protagonistas de esta serie manifiestan, por lo tanto, la intención de provocar siempre la risa, actitud que llega al exceso y al lenguaje políticamente incorrecto. De este modo, se delinea el ethos del actor como personaje cómico, situándolo en un imaginario sociodiscursivo que corresponde al estereotipo bien definido del personaje pícaro y golfo, y al mismo tiempo perdedor que consigue un punto de humor incluso en situaciones dramáticas (Amossy, 2010: 44-48). Se consolida el cliché del personaje gracioso que tiene que provocar la risa a la fuerza y que, de esta manera, consigue estrechar la relación con el público, quien se siente atraído por él y con el que se identifica, aunque se ponga en escena una parodia de la realidad, una exageración de las situaciones cotidianas.

En una perspectiva de futuro, sería útil el análisis de la atenuación en otros tipos de series (policiacas, médicas, judiciales, etc.) para seguir profundizando en el estudio del español de las series y en el conocimiento de la atenuación lingüística como fenómeno sociopragmático y discursivo. 


\section{normas}

Los procedimientos de atenuación en las series televisivas españolas| Giovanna Mapelli

\section{REFERENCIAS BIBLIOGRÁFICAS}

ALBELDA, Marta (2010): «¿Cómo se reconoce la atenuación? Una aproximación metodológica basada en el español peninsular hablado", en Orletti, Franca y Mariottini, Laura, eds., (Des)cortesía en español, Università Roma Tre, 41-70.

AlbeldA, Marta y CeStero, Ana María (2011), «De nuevo, sobre los procedimientos de atenuación lingüística», Español actual: Revista de español vivo, 969-940.

AlFIERI, Gabriella (2008): «La lingua della televisione», en Trifone, Pietro, ed., Lingua e identità. Una storia sociale dell'italiano, Roma, Carocci, 163-185.

ALFIERI, Gabriella y Bonomi, Ilaria (2012): Lingua italiana e televisione, Roma, Carocci.

Amossy, Ruth (2010): La présentation de soi. Ethos et identité verbale, Paris, Presses Universitaires de France.

AYLIFFE, David (2011): A study into the use of linguistic structures used inter-gender and intra-gender in the tv show Friends, MA dissertation, Anglia Ruskin University [en línea] $<$ https://sites.google.com/site/friendstvcorpus/>. [Consulta: 15/05/2016].

BAÑos PIÑERO, Rocío (2009): La oralidad prefabricada en la traducción para el doblaje. Estudio descriptivocontrastivo del español de dos comedias de situación: Friends y Siete Vidas. Tesis doctoral, Universidad de Granada.

BAÑOS PIÑERO, Rocío (2012): «La oralidad prefabricada en la traducción para el doblaje y en producciones propias: el caso de Friends y Siete Vidas", en Martínez Sierra, Juan José, ed., Fotografía de la investigación doctoral en traducción audiovisual, Madrid: Bohodón Ediciones, 99-117.

BAÑOS PIÑERO, Rocío (2013): “'That is so cool': investigating the translation of adverbial intensifiers in EnglishSpanish dubbing through a parallel corpus of sitcoms», Perspectives, 21/4, 526-542.

BAÑOS PIÑERO, Rocío et alii (2013): Corpus linguistics and Audiovisual Translation: in Search of an Integrated Approach, Special Issue of Perspectives, 21.

BednAREK, Monika (2010): The Language of Fictional Television: Drama and Identity, London/New York, Continuum.

BEDNAREK, Monika (2011): «The stability of the televisual character: A corpus stylistic case study», en Piazza, Roberta, Bednarek, Monika y Rossi, Fabio, eds., Telecinematic Discourse: Approaches to the Language of Films and Television Series, Amsterdam/Philadelphia, John Benjamins, 185-204.

BEDNAREK, Monika (2012): "Constructing 'Nerdiness': Characterisation in The Big Bang Theory», Multilingua, 31, 199-229.

BEDNAREK, Monika (2015): «Corpus-assisted multimodal discourse analysis of television and film narratives», en Baker, Paul y McEnery, Tony, eds, Corpora and Discourse Studies. Basingstoke/New York, Palgrave Macmillan, 63-87.

BONSIGNORI, Veronica y BRUTTI, Silvia «Across lingua-cultures: introductions and wishes in subtitled tv series», en Garzelli, Beatrice y Baldo, Michela, eds., Subtitling and intercultural communication, Pisa, ETS, 77-100.

BRIz, Antonio (1998): El español coloquial en la conversación. Esbozo de pragmagramática, Barcelona, Ariel.

BRIz, Antonio (2003): «La estrategia atenuadora en la conversación cotidiana española”", en Bravo, Diana, ed., Actas del Primer Coloquio del Programa EDICE: La perspectiva no etnocentrista de la cortesía: Identidad sociocultural de las comunidades hispanohablantes, Universidad de Estocolmo, Departamento de Español, 17-46.

BRIZ, Antonio y ALBELDA, Marta (2013): «Una propuesta teórica y metodológica para el análisis de la atenuación lingüística en español y portugués. La base de un proyecto en común (ES.POR.ATENUACIÓN)», ONOMÁZEIN, 28, 288-319.

Brown, Penelope y LEVInson, Stephen (1987): Politeness: Some universals in language usage, Cambridge, Cambridge University Press.

BUBEL, Claudia (2011): «Relationship impression formation: How viewers know people on the screen are friends», en Piazza, Roberta, Bednarek, Monika y Rossi, Fabio, eds., Telecinematic Discourse: Approaches to the Language of Films and Television Series, Amsterdam/Philadelphia, John Benjamins, 225-248.

CAFFI, Claudia (1999): «On mitigation», Journal of Pragmatics, 31, 881-909.

CALVI, Maria Vittoria (2007): «ll si replicativo spagnolo e la sua traduzione in italiano», en San Vicente, Félix, ed., Partículas. Particelle. Estudios de lingüística contrastiva español e italiano, Bologna, CLUEB, 259-267.

CARRIÓn, Jorge (2015): «Pensamos en serio porque pensamos en serie», Revista Mercurio, 176, 6-7.

Charaudeau, Patrick / Maingueneau, Dominique, dir, (2002): Dictionnaire d'analyse du discours, Paris, Seuil. 


\section{normas}

Los procedimientos de atenuación en las series televisivas españolas| Giovanna Mapelli

CHAUME, Frederic (2001), «La pretendida oralidad de los textos audiovisuales», en Agost, Rosa y Chaume, Frederic (eds.), La traducción en los medios audiovisuales, Castelló, Publicacions de la Universitat Jaume I, 77-88.

CHIERICHETTI, Luisa (en prensa): «Discurso amoroso e identidad en la ficción audiovisual: el caso de LEX».

FRASER, Bruce (1980): «Conversational mitigations», Journal of Pragmatics, 4, 341-350.

GOFFMAN, Erving (1973): La mise en scène de la vie quotidienne 1. La Présentation de soi, Paris, Minuit.

GÓMEZ CAPUZ, Juan (2001): «La interferencia pragmática del inglés sobre el español en doblajes, telecomedias y lenguajes coloquial: una aportación al estudio del cambio lingüístico en curso», Tonos Digital, 2 [en línea], $<$ https://www.um.es/tonosdigital/znum2/estudios/Doblaje1.htm>. [Consulta 10/10/2015]

Grasso, Aldo (2007): Buona maestra. Perché i telefilm sono diventati più importanti dei libri e del cinema, Milano, Mondadori.

GREGORY, Michael y CARROLL, Suzanne (1978): Language and situation: Language varieties and their social context, London, Routledge.

GRIGNAFFINI, Giorgio (2012): I generi televisivi, Roma, Carocci.

KovAccI, Ofelia (1999): «El adverbio», en Bosque, Ignacio y Demonte, Violeta, coords., Nueva gramática descriptiva de la lengua española, Madrid, Espasa-Calpe, 3, 705-786.

LA FORGIA, Francesca y TONIN, Raffaella (2016): «ll parlato delle serie televisive: il caso di Cuéntame e di Boris», Orillas, 5, [en línea] <http://orillas.cab.unipd.it/orillas/05_08toninlaforgia_astilleros/>. [Consulta 20/10/2016].

LAKOFF, George (1972): «Hedges: a study in meaning criteria and the logic of fuzzy concepts», Journal of Philosophical Logics, 2, 458-508.

MAINGUENEAU, Dominique [en línea] "L'ethos, de la rhétorique à l'analyse du discours", versión reducida y ligeramente modificada de «Problèmes d'ethos", Pratiques, 113-114, juin 2002, $<$ http://dominique.maingueneau.pagesperso-orange.fr/texte06.html >. [Consulta 11/08/2016].

MAPELLI, Giovanna (2016): «Aspectos de la oralidad en las series televisivas españolas: los procedimientos de intensificación», Orillas, 5, [en línea] <http://orillas.cab.unipd.it/orillas/es/05_09mapelli_astilleros/>. [Consulta 20/10/2016].

MARTín ZORRAQUINO, Antonia y PORTOLÉS, José (1999), «Los marcadores del discurso», en Bosque, Ignacio y Demonte, Violeta, eds., Gramática descriptiva de la lengua española, Madrid, Espasa-Calpe, 4051-4213.

MELLONI, Alessandra (2004): Tra immagine e parola. Costruzione del racconto e varietà discorsive nella fiction cinetelevisiva ispanica, Salerno, Oèdipus.

MENDUNI, Enrico (2002): I linguaggi della radio e della televisione. Teorie e tecniche, Roma/Bari, Laterza.

NENCIONI, Giovanni (1976): Di scritto e di parlato. Discorsi linguistici, Bologna, Zanichelli.

Provencio GaRRIGós, Erminia (2009): «La prefijación y la sufijación», en Ruiz Gurillo, Eleonor y Padilla García, X. eds., Dime cómo ironizas y te diré quién eres, Frankfurt am Main, Peter Lang, 241-265.

QuAGLIO, Paulo (2009): Television dialogue: the sitcom Friends vs. natural conversation, Amsterdam/Philadelphia, Johns Benjamins.

RuIz GURILLo, Leonor (2012): La lingüística del humor en español, Madrid, Arco/Libros.

RuIz GURILLO, Leonor (2013): «El monólogo humorístico como tipo de discurso. El dinamismo de los rasgos primarios», Cuadernos AISPI, 2, 195-218 [en línea]: <http://www.aispi.it/wp-content/uploads/Cuaderno2013-2-el-monologo-humoristico-como-tipo-de-discurso-el-dinamismo-de-los-rasgos-primarios.pdf>. [Consulta 10/05/2016]

TIMOFEEVA, Larissa (2009): «Las unidades fraseológicas», en Ruiz Gurillo, Eleonor y Padilla García, X. eds., Dime cómo ironizas y te diré quién eres, Frankfurt am Main, Peter Lang, 193-217.

TONIN, Raffaella (2014): «Un poquito de por favor: la sfida dell'oralità alle limitazioni del sottotitolo», Cuadernos AISPI, 4, 213-228, [en línea] <http://www.aispi.it/wp-content/uploads/Cuaderno-2014-4-un-poquito-de__por-favor___la-sfida-delloralita-alle-limitazioni-del-sottotitolo.pdf>. [Consulta 20/10/2016].

WEBB, Stuart (2010): «A Corpus Driven Study of the Potential for Vocabulary Learning through Watching Movies», International Journal of Corpus Linguistics, 15/4, 497-519.

Yus, Francisco (2015): «Discourse and identity», en International Encyclopedia of the Social \& Behavioral Sciences (2. ed.), vol. 6, Oxford, Elsevier, 3728-3732. 